\title{
AUTONOMIA DISCENTE NA UNIVERSIDADE: METODOLOGIAS ATIVAS E A CIBERCULTURA
}

\author{
Patrícia Lupion Torres \\ Rui Trindade \\ Virgínia Bastos Carneiro
}

É encontrada em concepções de Dewey, a certeza de que a prática democrática, no âmbito superior, alinha a convencional articulação entre o indivíduo e a sociedade, seja esse rumo observado tanto na esfera de processos metodológicos ativos de ensino, como na atitude autônoma discente com vistas a transformações da sociedade, ou ainda, na conduta de liberdade de ação, criação e vivência de experiências ativas em rede (CUNHA, 2011). Esse entendimento de ideal democrático educativo, no qual os interesses se interligam mutuamente, torna pertinente a congruência democrática, especialmente se dispostos variados aspectos de participação do interesse comum, como também “maior confiança no reconhecimento de serem, os interesses recíprocos, factores da regulação e direção social” (DEWEY, 1952, p. 126).

As duas considerações, tanto a participativa quanto a de regulação e direção social, são precisamente as que traçam uma sociedade democraticamente fundamentada. Reforça-se essa constituição democrática com o arrazoado de Dewey (1952, p. 119) sobre a educação ser “uma função social que assegura a direcção e o desenvolvimento dos imaturos, por meio de sua participação na vida da comunidade a que pertencem ...”, e que ela

[...] variará de acordo com a qualidade da vida que predominar no grupo. É particularmente verdade o facto de que uma sociedade que, não somente muda, mas que, também, para estimulá-la, faz da mudança um ideal, terá normas e métodos educativos diferentes dos de outra que aspire meramente à perpetuação de seus próprios costumes.

Ademais, somente a educação democrática, com especial ênfase na perspectivado ensino superior e no entendimento de autonomia discente, pode atender a ideais em constantes transformações, sugerindo que uma democracia é mais do que uma forma de governo; é, substancialmente, "uma forma de vida associada, de experiência conjunta e mutuamente comunicada” (DEWEY, 1952, p. 126).

A articulação institucional superior pressupõe, neste contexto democrático, determinar um cidadão emancipado e participativo no sentido de um pensar e de um aprender próprio, de um “aprender a aprender” como postura autônoma. Deste modo, Dewey ressalta a importância de um desencadeamento - o da cidadania à prática social e o da liberdade ao exercício da vida real - por 
meio do exercício de suas capacidades intelectuais (LOURENÇO FILHO; MENDONÇA, 2014). Assume-se desta estreita ligação, a do exercício da cidadania na democracia e a da qualidade da formação educacional e cultural nos discentes, que o pensar e o agir desenvolvidos pelo aprender a aprender estão assentados em princípios aprendidos e eleitos como confiáveis e justos (CARNEIRO, 2018).

Um dos temas de estudo da Educação na atualidade é o desenvolvimento da autonomia discente diretamente ligada à renovação do perfil do aluno universitário, face ao desdobramento de mudanças de comportamentos e de valores da sociedade, especialmente configurados pelo desenvolvimento e uso de tecnologias digitais (TORRES, HILU, SIQUEIRA, 2015), visando o desenvolvimento de uma consciência democrática.

Tentando acompanhar esta mudança de contexto social estão instituições de ensino superior dispostas a implantar alternativas metodológicas com a finalidade de atingir as atuais demandas culturais, educacionais e tecnológicas, políticas e econômicas. Assim, o jeito de ser discente na atualidade pede renovada construção de postura face ao aprendizado, em especial ao desenvolvimento da autonomia do estudante.

A necessidade de mudança para uma atuação protagonista do estudante é ampliada de forma significativa a partir do aumento do uso de tecnologias digitais de informação e comunicação (TDICs) e de tecnologias móveis e sem fio (TMSF) já que determinam, desde muito, a organização social em redes em outros tempos e espaços. Essas evoluções tecnológicas fornecem a base material para a expansão das redes que passam a penetrar em toda a estrutura social (CASTELLS, 1999) e tem papel significativo na construção de sociedades mais democráticas. Esse autor destaca ainda que

[...] essa lógica de redes gera uma determinação social em nível mais alto que a dos interesses sociais específicos expressos por meio das redes: o poder dos fluxos é mais importante que os fluxos do poder. A presença na rede ou a ausência dela e a dinâmica de cada rede em relação às outras são fontes cruciais de dominação e transformação de nossa sociedade: uma sociedade que, portanto, podemos apropriadamente chamar de sociedade em rede, caracterizada pela primazia da morfologia social sobre a ação social (CASTELLS, 1999, p. 565).

\section{A ATUALIDADE DA ESCOLA NOVA NA CIBERCULTURA}

Há mais de século, a autonomia já era entendimento e base de formação discente e de aprimoramento para seu crescimento educacional, cultural e principalmente humano. Ao longo de 
seus 92 anos de idade, John Dewey (1890-1952), evidencia seu pensamento de reformador da educação nos meios culturais controversos dos Estados Unidos sob a conviç̧ão moral de que “democracia é liberdade”, inclusive no meio educacional (WESTBROOK; TEIXEIRA, 2010).

Neste período, a dimensão social da comunidade traz muito da representação educacional de Dewey, especialmente quando "reflete as finalidades da educação [...] e a sua articulação com a dinâmica das sociedades democráticas” (TRINDADE 2012, p. 60). Nas articulações sobre o autor americano, de que "a vida social [...] é a base a partir da qual ocorre e explica toda a sua formação e crescimento”, continua Trindade (2010, p. 60), fica evidente que a instituição educacional é o local onde ocorre a educação formal da aprendizagem integrada à vida, sua relação com o real, com a aplicabilidade, com o uso e como função prática na vida. O próprio Dewey (1978, p. 36) determina suas reflexões com a seguinte frase: “Educação é vida, não preparação para a vida”. Tais reflexões, embora elaboradas para o contexto escolar, cabem também para o contexto universitário.

Ao invocar um contexto mais proativo das instituições de ensino, têm-se a valorização dos estudantes presentes nos seguintes enunciados:

A centralidade da criança no âmbito das escolas e do mundo contemporâneo; a importância da sua atividade enquanto condição primeira das aprendizagens que efetua; a necessidade de se alargar e encontrar outros recursos educativos para além daqueles que o costume pedagógico consagrou; a redefinição do papel dos professores como docentes e a configuração das novas dinâmicas que se desenvolvem nas [universidades] para se estabelecer os programas de trabalho ou a importância do auto-governo, quer como finalidade educativa, quer como instrumento de gestão do quotidiano (TRINDADE, 2012, p. 29).

Estas articulações do movimento da Escola Nova evidenciaram uma consciência de proposta educacional crítica em relação ao modo tradicional de ensino e aprendizagem. Deste modo, a partir da perspectiva escolanovista - da autonomia prática voltada para a ação - pretende-se fazer uma apreciação reflexiva da autonomia na atualidade metodológica educacional ativa que prepara para uma ação mais crítica e ativista em rede.

Justifica-se essa reflexão pela necessidade de formação de um estudante contemporâneo inserido em um panorama educacional global, social, histórico e político, no qual a autonomia é pressuposto que favorece reflexão e engajamento na resolução de problemas, na participação crítica em redes e na reestruturação de novos conhecimentos.

Acontece de modo recorrente no senso comum, a ideia de que a comunicação e a informação - derivada dos e propagada por meios midiáticos na cibercultura - consegue dar conta de 
promover uma participação conteudista satisfatória e integrante do homem à sua vida em sociedade. Todavia, estudiosos da Educação mostram que, embora imprescindíveis, as informações não fazem sentido quando simplesmente memorizadas ou condenadas ao “achismo”. Elas trazem a sensação de mera reprodução e de enfoques vazios, forjando conhecimentos e "colocando os aprendizes na condição de espectadores do mundo” (BERBEL, 2011, p. 25). Na complexidade humana dos dias de hoje, a capacidade de pensar, a habilidade de refletir, observar e analisar dados é tão relevante quanto fundamental e imprescindível é a propagação de informações em redes. As redes permitem o circular de informação e aação crítica sobre essa informação, de forma a criar novos conhecimentos, já que "mais do que uma interligação de computadores, são articulações gigantescas entre pessoas conectadas com os mais diferenciados objetivos” (KENSKI, 2011, p.34). A cocriação e o compartilhamento deve se dar de forma responsável, para não haver a propagação de fakenews.

Na sua obra pedagógica, Dewey argumenta que o ensino deve acontecer pela ação e não pela instrução e formula que é na experiência produtiva de cada um que problemas têm suas resoluções. Valida como primordial as vivências reais com o ensino observando educação como renovação de experiência sem um fim imediato a ser atingido, mas como processo gradativo a ser vivenciado ao longo de toda a vida.

$\mathrm{Na}$ contextualização da Escola Nova, encontra-se como pano de fundo social o desenvolvimento e o progresso de uma sociedade capitalista e a necessidade de reconstruir um novo homem dentro da burguesia social. Deste modo, vivenciar experiências na vida e na educação, são realidades inseparáveis na concepção de Dewey, assim como o cenário democrático é necessário à construção de experiências e de conhecimento (DEWEY, 2007).

Autores como Bacich, Tanzi Neto e Trevisani (2015), Trindade (2012) Torres et al. (2017) compreendem que as metodologias ativas são uma concepção educativa que estimula a crítica e a reflexão, tão necessárias no processo de ensino e aprendizagem em um contexto de cibercultura. Educador e educando participam ativamente do processo, em situações de aproximação crítica da experiência com a realidade. Esses autores ainda discorrem que na docência o professor que intermedeia os saberes, precisa se mostrar atento para ações que levem o aluno a trabalhar a autonomia como ação cotidiana, não somente com vistas à elaboração de um conhecimento, mas também, paralelamente e de modo intrínseco, como viés de desenvolvimento humano e pessoal. 
É na clareza do cenário educacional da atualidade, em que emerge a aprendizagem ubíqua ${ }^{1}$ (SANTAELLA, 2010) que urge rever o processo de ensino e aprendizagem, tendo em mente a função do aluno-protagonista, autônomo em seu aprendizado. Assim é que a aprendizagem ativa se apresenta como alternativa para uma educação inovadora e em harmonia com as novas exigências de construção do conhecimento na cibercultura (TORRES; IRALA, 2007).

Essas novas exigências educacionais determinam "transações em lugar de transmissões, interações em lugar de emissões, numa reengenharia radical do espaço áulico que encoraja a aprendizagem socialmente aberta” (SANTAELLA, 2012, p. 326).

Portanto, a atenção contemporânea ao ensino e à aprendizagem desenvolvida a partir de âncoras fixadas no aluno como protagonista de seu trabalho, na construção consciente dos saberes por meio de ação autônoma e ativa são requisitos de pensamentos presentes na Escola Nova que, no momento atual, globalizado e tecnológico, coincidem com as necessidades educacionais e humanas (DEWEY, 2007).

\section{JOHN DEWEY - DA EDUCAÇÃO TRADICIONAL À ESCOLA NOVA}

O filósofo, psicólogo e pedagogo norte-americano, John Dewey, considerado destaque na arte educacional vinculada à democracia e à integração teoria/prática, idealizou uma pedagogia na qual a aprendizagem se dá pela ação - learningbydoing - ou seja, aprender fazendo. Postula que a educação se concretiza na reflexão produtiva e fértil, de modo que toda a prática tem um fim social; fica evidente uma formação humana que proporciona um equilíbrio social, isto é, a democracia considerada não apenas um regime de governo, mas uma forma de vida (DEWEY, 2007).

Não é possível abordar assuntos respectivos a ensinar e aprender de modo dissociado de mediações políticas ou culturais caracterizadas pela sociedade em suas diversas épocas, tempos e histórias específicas. Assim, enuncia-se os modelos pedagógicos - reconhecidos como paradigmas pedagógicos - a partir do século XVIII, para contextualizar o presente artigo.

O primeiro deles, de acordo com Trindade e Cosme (2010, p. 32), é o “paradigma da instrução" percebido no viés de evidência à desvalorização do discente como elaborador do conhecimento ao não possibilitar que se assuma como autoconstrutor, formulador de análises ou

\footnotetext{
${ }^{1}$ Aprendizagem ubíqua: de acordo com Santaella, é a aprendizagem disponível a qualquer momento. É quando a informação, por meio de dispositivos móveis, é incorporada para usos futuros. Trata-se de uma aprendizagem coletiva, baseada na troca de informações e conhecimentos, que se interpenetram com a educação formal. Disponível em: <https://www.revistaensinosuperior.gr.unicamp.br/edicoes/edicoes/ed09_abril2013/NMES_1.pdf>. Acesso: 21/01/19.
} 
questionamentos, uma vez que suas respostas são mais valorizadas do que suas indagações; a expressão do saber coisificado advém do processo seguro de omnipotência dos professores magistrocentrismo - que, ao ditar os conteúdos que precisam ser conhecidos, espera dos alunos a oportunidade de aplicar o que lhes foi transmitido, tal qual um manual escolar informativo e organizado deveria ser. Trindade e Cosme (2010, p. 32) explicam a educação neste período como uma concepção que,

[...] ao assumir uma dimensão eminentemente prescritiva do ato educativo, tende a valorizar, sobretudo, a difusão da informação e a aquisição de aptidões específicas por parte dos alunos, através da utilização de metodologias que se caracterizam pela sua sistematicidade estandardizada e se polarizam, sobretudo, nos conteúdos a apreender.

Estas são características que denotam na pessoa do professor a relação maior com o saber, completamente dissociado da dimensão cognitiva dos alunos e de sua bagagem cultural.

O segundo dos paradigmas, na contemplação de Trindade e Cosme (2010), é o "paradigma da aprendizagem”, que emerge com estudos da Psicologia da Educação de conformidade ao respeito à natureza infantil, ação consciente e visível dos pedagogos da Escola Nova, que se veem, doravante, embasados em preceitos da psicologia como suporte aos entendimentos da infância. À vista disso, percebe-se o aluno no centro do processo de ensino e aprendizagem para considerações, tanto de ordem de currículo, como de potencialização de suas necessidades e interesses, no qual

[...] o acto de aprender se encontra mais relacionado com o desenvolvimento de competências cognitivas e relacionais do que com a apropriação de conteúdos construídos por outros. Deste modo, aprende-se quando somos estimulados a pensar e a aprender a aprender, porque, nesta abordagem, é o desenvolvimento cognitivo dos sujeitos e das dinâmicas endógenas que lhe estão subjacentes que poderão garantir a ocorrência de aprendizagens (TRINDADE; COSME, 2010, p. 44-45).

Assim, está na valorização do sujeito que aprende, o fato de processar as informações pelo aprender a aprender, considerado nesta perspectiva como um desafio para as escolas, pois passam a se constituir "em espaço capaz de promover e suscitar aprendizagens” (TRINDADE; COSME, 2010, p. 46).

Como terceiro paradigma, os autores indicam o "paradigma da comunicação”, como aquele processo de ensino e aprendizagem que “depende da qualidade e da pertinência das interacções que se estabelecem entre os professores e os alunos, ou os alunos e professores entre si, a propósito das relações estrategicamente distintas que ambos estabelecem com o saber” (TRINDADE; COSME, 2010, p. 58). Ao valorar as mais diferentes maneiras de interação que se produzem dentro (e sempre 
que possível fora) da sala de aula como estimuladoras de um processo de ensino e aprendizagem, a dinâmica de apropriação de um patrimônio cultural, e mesmo de afirmação pessoal e social de desenvolvimento, são alguns dos “contributos matriciais” para este paradigma.

Desta forma:

[...] todos os conceitos e todas as teorias estão interconectados. Não há conceitos em hierarquias. Uma ciência ou uma disciplina não é mais importante do que a outra. A visão do conhecimento em rede constitui um instrumento para a transformação potencial do próprio conhecimento. Reconhece-o como um processo, algo que não possui um aspecto definível absolutamente fixo. [...] Implica um sistema aberto à participação, uma estrutura dissipadora e que está em constante fluxo de energia, capaz de crescimento e transformação sem fim. A imagem de rede, tanto do conhecimento em rede como de redes de conhecimentos, pressupõe flexibilidade, plasticidade, interatividade, adaptabilidade, cooperação, parceria, apoio mútuo e autoorganização (MORAES, 1997, p. 96).

É ainda por meio do diálogo que se acorda, se debate e se compreende os pares do dueto educacional - professor/aluno e aluno/aluno - de forma ativa, interativa e colaborativa, que acontece uma aprendizagem ativa, à procura de respostas e soluções para as mais variadas propostas de construção de conhecimentos.

As novas gerações encontram-se inseridas em diversas redes e não concebem seu cotidiano sem interações e trocas e compartilhamentos constantes e rápidos de informações. Sendo assim, na medida em que a universidade tem papel incontestável na formação do caráter discente, pode vir a transformar fundamentalmente a realidade da sociedade.

Para identificar a teoria proposta por Dewey, têm-se nas palavras instrumentalismo ou funcionalismo, as que melhor a designam, uma vez que "ideias são hipóteses de ação e, como tal, são verdadeiras à medida que funcionam como orientadoras da ação” (ARANHA, 2006, p. 261). Neste contexto, ideias têm valor instrumental para solucionar situações-problema na experiência humana.

Não é por mera causalidade que os partidários da educação tradicionalista - em cujo âmago educacional está um discente de personalidade dócil e disciplinada - fizeram forte objeção ao pensamento de Dewey. Armados de teorias “centradas no programa” com instrução gradual em disciplina rígida para a aquisição dos saberes, o que se espera dos alunos é um simples acolhimento e aceite dos ensinamentos professorais. Os tradicionalistas defendem ainda, conhecimentos formados ao longo dos séculos com forte negação ao espaço de individualidade ao aluno em sala de 
aula; logo, ideais pragmáticos e progressivos, liberais e autônomos como os de Dewey seriam algo caótico, anárquico e uma rendição da autoridade dos adultos aos jovens alunos (DEWEY, 1964).

Como viés de educação progressiva, a Escola Nova propõe crescimento constante na vida, na medida em que se multiplicam as experiências, e o controle sobre elas (ARANHA, 2006). Na cibercultura temos as experiências se multiplicando de forma exponencial, fato que determina a necessidade de uma formação crítica e reflexiva, que prepare os alunos para interagir de forma ética em uma sociedade em que "a velocidade das transformações sociais é instaurada pelos avanços tecnológicos dos dispositivos digitais, onde o tempo e espaço são subjetivos e ao mesmo tempo contínuo” (ROSSINI; SANTOS, 2015, p. 21).

Em contexto metodológico, Torres e Irala (2007, p. 71) confirmam influências de compartilhamento de experiências na seguinte frase:

[...] suas filosofias exerceram grande influência para importantes mudanças na sociedade, tais como: a relação de dependência entre a aprendizagem a as atividades sociais, a influência do ambiente físico no desenvolvimento da cultura e a necessidade de promoção das diferenças individuais [...].

Outro tópico escolanovista, está na sensibilidade do educador em descobrir os verdadeiros interesses do aluno, visto que desse modo, experiências que lhes falem de perto, adquirem, para os discentes, valor educativo mais significativo. Vem dessa valorização a condição de permitir melhor compreensão do entorno, maior observação nos espaços para a descoberta, para o desenvolvimento e para a construção dos saberes (ARANHA, 2006; TRINDADE, 2012).

\section{AUTONOMIA - ORIGEM E CONCEITOS}

Do ponto de vista etimológico, a palavra autonomia vem do grego e é formada pelo adjetivo autos, que significa “o mesmo”, “ele mesmo”, “por si mesmo” e pela palavra nomos cujo significado é “nomes”, porém pode ser entendida como normas ou regras. Significa, de acordo com o dicionário Houaiss (HOUAISS, 2001, p. 351): “autônomo: que tem autonomia. 1. Dotado da faculdade de determinar as próprias normas de conduta, sem imposições de outrem (diz-se de indivíduo, instituições, etc.) [...] 3. Que tem o direito de se governar segundo as suas leis e costumes.”

Assim, compreende-se autonomia como o direito do homem de reger-se por leis próprias, como ser racional e livre que é, capaz de tomadas de decisões com independência moral e intelectual. 
No século XX, Freire (2015) expressa autonomia em uma linha dialógica centrada em perspectiva pedagógica progressista, ou seja, aquela que reconhece na identidade cultural e nos contornos fundamentados na ética, no respeito à dignidade e na própria autonomia do educando, o sujeito sócio-histórico-cultural. Na sua pedagogia da autonomia, Freire (2015) a relaciona como elemento constitutivo da compreensão da prática docente, assim como a autonomia da formação discente, uma vez que a reconhece como curiosidade ingênua e epistemológica, como rigorosidade ética, como pesquisa, como crítica, como aceitação do novo, como rejeição a qualquer forma de discriminação, como liberdade, como capacidade de tomadas de decisão, como tolerância e humildade. Autonomia como coerência na dialogicidade. Dialogicidade ampliada na cibercultura pelo aumento do fluxo de comunicação, interação, compartilhamento, troca e autoria.

Na complexidade de Morin (2011), a autonomia se encontra no aprender a aprender “separando e religando”, “analisando e sintetizando”. A tessitura da complexidade do sociólogo e filósofo francês demanda uma reforma de pensamento, que em última análise é uma reforma de vida, uma verdadeira metamorfose, na qual ser autônomo faz parte da identidade da condição humana.

\section{METODOLOGIAS ATIVAS E A PERTINÊNCIA DA ATUALIDADE PROPOSTA POR DEWEY}

No contexto educativo atual, influenciado pelos processos de comunicação e aprendizagens ubíquas (SANTAELLA, 2009; 2013) as metodologias ativas mostram-se determinadas a remodelar concepções tradicionais do processo de ensino e aprendizagem ao destacar na prática seu lado social e de interatividade, seu viés humano e globalizante, reconhecido no conhecimento prévio que cada estudante traz como bagagem pessoal, como know-how e como compreensão integral de mundo (TORRES; IRALA, 2007).

Entretanto, na esteira pedagógica e metodológica, instituições escolares que hoje se apresentam, ainda agora, em pleno século XXI, com características estruturais tradicionais do século XVIII, se deparam com alunos nativos digitais de natureza comportamental e social embasados no dinamismo das redes sociais, na agilidade e fluidez das informações. Autores como Prensky (2001), Bauman (2001), Torres e Irala, (2007) destacam que a realidade atual demanda novos conceitos metodológicos de ensino e aprendizagem para a renovação da construção do conhecimento.

Para Berbel (2011, p. 28), está nas características de aguçar curiosidade e incrementar novos apelos “de engajamento, percepção de competência e de pertencimento, além da persistência nos 
estudos”, o real valor das metodologias ativas como contribuição que renova o aprender ativo. As considerações de Dewey (2007) de vida-experiência-aprendizagem, podem se mesclar aos apelos contemporâneos de Berbel (2011) para a formação de cidadão consciente da premência da autonomia, na formação de seu caráter.

Também Moran (2015), cogita sobre uma nova estrutura metodológica ativa para a atualidade, ao enfatizar uma necessária mudança no processo de ensino e aprendizagem, porém com observância para o complexo impasse de capacitação e formação continuada de professores. Transformações levam a inevitáveis desestruturações e consequentes reorganizações: o que demanda tempo e um aguçado sentimento de atualização (BACICH; TANZI NETO; TREVISANI, 2015).

Para o entendimento de metodologias ativas, recorre-se à Bastos (2006, p. 1):

Metodologias ativas são processos interativos de conhecimento, análise, estudos, pesquisas e decisões individuais ou coletivas, com a finalidade de encontrar soluções para um problema. É o processo de ensino em que a aprendizagem depende do próprio aluno. O professor atua como facilitador ou orientador para que o estudante faça pesquisas, reflita e decida por ele mesmo, o que fazer para atingir um objetivo.

Nesta percepção de aprendizagem, a de encontrar soluções para um problema, Bastos (2006) converge para o aluno a responsabilidade do seu aprendizado com base em reflexões e decisões de modo pessoal ou coletivo. Na troca de ideias entre pares processa-se a interação, alia-se camaradagem com postura de discernimento, de crítica e de responsabilidade para com o resultado a que se almeja. Este objetivo comum, ou seja, o resultado de um determinado trabalho contém em si a aprendizagem colaborativa ao ter como escopo "atividades de grupo que pretendem um objetivo em comum, implicando a regularidade da troca, o trabalho em conjunto, a constância da coordenação” (TORRES; IRALA, 2015, p. 61).

Sob o prisma, tanto das metodologias ativas, como o da aprendizagem colaborativa, o imbricar das atenções leva a reflexões sobre autonomia discente ao analisar o fato da responsabilidade sobre o aprendizado, da experiência compartilhada e da interdependência do trabalho. A autonomia é construída culturalmente na relação do homem com a sociedade, na cibercultura, com seus semelhantes, na relação dialógica, nas indagações, nas análises das várias dimensões apresentadas.

Na medida em que a essência da pedagogia escolanovista está na aprendizagem processual e na experiência do cotidiano aliada à resolução de problemas é que a convergência do processo da 
autonomia se aproxima da aprendizagem ativa. Freire (2015, p. 105), pondera que "a autonomia vai se constituindo na experiência de várias, inúmeras decisões que vão sendo tomadas” e que "a autonomia, enquanto amadurecimento do ser para si, é processo, é vir a ser”.

Na perspectiva de autonomia como processo formativo do ser humano, tão necessário na atualidade no contexto da cibercultura, considera-se aproximar a autonomia discente às práticas metodológicas ativas contemporâneas. Assim, duas práticas de metodologias ativas serão abordadas neste artigo: o método de projetos ou $P J B L$ e o método de resolução de problemas ou $P B L$.

O método de projetos, ou PJBL - termo do inglês Project Based Learning - trata de atividades que gradativamente se incorporam à Escola Básica, em especial em estudos de projetos transversais e interdisciplinares, com trabalhos em equipe. Conceitua-se de acordo com Bordenave e Pereira (1982, p. 233), como:

[...] atividades que redundam na produção, pelos alunos, de um relatório final que sintetize dados originais (práticos ou teóricos), colhidos por eles, no decurso de experiências, inquéritos ou entrevistas com especialistas. O projeto deve visar à solução de um problema que serve de título ao projeto.

As considerações de Bordenave e Pereira (1982) pedem postura discente com capacidade para solucionar problemas, na qual todas as etapas do projeto são vivenciadas como se fosse uma situação real visando como último objetivo, a solução de um problema. Demanda posicionamento reflexivo, responsável e independente por parte do aluno.

De igual modo, Krajcik e Blumenfeld (2006) definem PJBL como um método de ensino e aprendizado ativo no qual os estudantes adquirem conhecimentos ao trabalhar investigativamente para responder a um desafio, problema ou questão complexa.

Também, de acordo com Krajcik e Blumenfeld (2006), as raízes do PJBL encontram-se nos trabalhos do filósofo escolanovista norte-americano ao descrever que eram das situações reais da vida, do cotidiano ordinário, de tarefas significativas e problemáticas comuns que surgiam os melhores comprometimentos dos alunos.

Com o passar dos anos, foi refinada a percepção original de Dewey. O aprender de modo ativo atual - por meio de metodologia de projetos - permite maior compreensão, participação e interesse para os estudantes. Ainda de acordo com Krajcik e Blumenfeld (2006), como consequência da construção de conhecimento a partir de um contexto significativo e real, está a autenticidade das novas experiências, uma vez que estabelecem conexões e vínculos com a 
realidade. Trabalhos explorados em sala de aula servirão como âncora para a elaboração de projetos no mundo real.

Desse modo, o desenvolvimento da autonomia discente acontece no processo da prática, na criatividade de tomadas de decisão e na flexibilidade do “jogo de cintura”, necessários ao alcance do objetivo final. As práticas em questão levam a um aprendizado que demanda, necessariamente, um caráter consciente, comprometido e crítico por parte dos estudantes hoje tão inseridos no mundo digital.

Como segunda metodologia ativa, apresenta-se o método por meio de resolução de problemas ou PBL, sigla em inglês que designa Problem Based Learning ou aprendizagem baseada em problema. Uma das referências centrais é a importância do “método da descoberta” - que toma como base epistemológica o envolvimento ativo dos alunos para resolver problemas, conjeturar e discutir impasses por meio de descoberta e da exploração de alternativas, estabelecer similaridades e relações entre ideias. Outro princípio importante é a aprendizagem em espiral que permite ao estudante analisar um mesmo tema de acordo com diferentes níveis de profundidade e em diferentes modos de representação (BENDER, 2014).

Nestas bases, o PBL se organiza em torno de problemas inter e transdisciplinares imbricando componentes teóricos e práticos com ênfase no desenvolvimento cognitivo. Apresenta caráter formativo na medida em que estimula uma atitude ativa do aluno em busca do conhecimento. Uma vez que a aprendizagem não é entendida como um processo de recepção, mas de construção do conhecimento, pressupõe:

1. conhecimento prévio sobre o assunto, mesmo que empírico ou fruto de uma experiência;

2. elaboração de estruturas cognitivas para o resgate dos conhecimentos prévios relevantes;

3. motivação epistêmica através das colocações e discussões sobre a busca da resolução do problema;

4. aprendizagem é pautada na metacognição e em fatores sociais.

Ao trabalhar de modo colaborativo, os estudantes assumem papeis condizentes com sua futura atuação profissional em contextos reais ou virtuais. A aprendizagem se sustenta em etapas a partir de uma problematização: início, direcionamento, motivação e foco.

O principal objetivo é de uma aprendizagem que parte da estrutura de um problema real e do desenvolvimento de habilidades autônomas e de trabalho em equipe, ou individual, como acontece em situações práticas. O professor atua como mediador ou facilitador da aprendizagem ao orientar o 
discente na busca por informações e ao encorajá-lo a debates colaborativos para a definição ou encaminhamento de soluções para o problema.

A última fase é a da autoavaliação ou da avaliação de seus pares com a intenção de desenvolver habilidades avaliativas e de autopercepção.

Assim, permite-se cogitar a aprendizagem ativa - seja por meio da prática de projetos ou de problemas, em uma sociedade de características tecnológicas cujo aperfeiçoamento e rapidez transformam o cotidiano e o cenário sociocomportamental, metodológico e educacional - como reflexo direto do renovado aprender e ensinar e do construir conhecimento contemporâneo.

Alunos com perfis transformados pela sociedade tecnológica carecem de movimentos educacionais sensíveis ao novo momento. Ensino e aprendizagem por métodos de ação e praticidade acenam com melhorias no incrementar, no descobrir e no trabalhar este singular conhecimento, que ora vem de planos reais, ora de plataformas virtuais (BACICH; TANZI NETO; TREVISANI, 2015).

O espírito de iniciativa e independência no processo de ensino e aprendizagem, que levem à autonomia e ao autogoverno - predicados de uma sociedade democrática em Dewey - indicam, como já foi afirmado neste artigo, não somente uma diretriz governamental política, mas também, de reorganização da vida universitária, de ressignificação educacional metodológica e de interlocução e produção de cultura (TRINDADE, 2009).

\section{CONSIDERAÇÕES FINAIS}

Neste arrazoado reflexivo-crítico a respeito de autonomia discente sob a vertente escolanovista e a prática de metodologias ativas contemporâneas, identificou-se uma atualidade reinterpretada do “aprender fazendo” de Dewey nas práticas do processo ativo de ensino e aprendizagem. O modo progressivo e processual verificado no aprendizado atual proposto por metodologias ativas configura o ideário de interdependência entre a aprendizagem e as atividades sociais, assim como entre o ambiente físico e o desenvolvimento da cultura, patrimônios estes que se constituem princípios da Escola Nova (DEWEY, 2007).

A transposição do aprendizado colaborativo e da formação educacional universitária autônoma para a realidade contemporânea desvela significativas diretrizes em relação a condutas democráticas. Em suma, pode-se afirmar que o processo educativo universitário ganha propósitos sociais e políticos importantes na medida em que reforça o exercício da cidadania e legitima um desenvolvimento democrático gradativo e contínuo aos discentes (DEWEY, 2007). 
Autores como Torres (2002) e Trindade (2012) ao trazerem amplitude nas oportunidades da aprendizagem colaborativa, do aprender entre pares e da conjugação de diálogos, abrem canais de convergências para a liberdade, para a oportunidade de críticas e flexibilidade de opiniões, para a manifestação de ações proativas e de tomadas de decisão que levam à redação de novos saberes e entendimentos democráticos. Assim,

[...] o conhecimento se processa como um liame, que é composta respectivamente pela ligação de vias e interconexões. As vias podem representar o indivíduo, o sujeito, o ser, o self, que ao mesmo tempo em que olha para si toma ciência da perspectiva do outro e se prepara para o coletivo. As interconexões representam as relações; em outros termos, às perspectivas individuais somam-se os entrelaçamentos decorrentes do outro, do coletivo, do temporal, do espacial, do contextual, do conjuntural etc. O liame é muito mais do que a mera composição de vias, interconexões, tramas e malha. Representa a vinculação dinâmica do todo, ou seja: das vias, das interconexões, do individual e do coletivo, do sujeito e do grupo, do tempo e do espaço, do contexto e das conjunturas, das ações e das atuações, da própria malha e da própria rede (TORRES, 2014, p. 18).

No contexto das práticas ativas $P J B L$ e $P B L$, percebeu-se espaço metodológico- educacional para que os discentes contemporâneos desenvolvam uma perspectiva de autogoverno, autônoma, frente às solicitações de atitudes investigativas e de reflexão sobre suas próprias experiências. Essas conjunções são como marcas contemporâneas da Escola Nova em cujo contexto de processo de aprendizagem ativo se valoriza a autonomia na formação dos aprendizes.

Em certa medida, refletir a autonomia discente, levando-se em conta metodologias ativas, traz conjuntamente uma compreensão sobre o modelo do ensino tradicional em relação ao emergente, na constatação do seu modus operandi de ensino. Salienta-se ainda que, o que distingue os dois campos educacionais "tem a ver com o modo como concebem a relação que os alunos estabelecem com o saber” (TRINDADE, 2012, p. 441). Esta relação que, no caso mais conservador, incide em subordinação do discente ao objeto de aprendizagem, no modelo contemporâneo de propostas ativas, tal vínculo se propõe resultante, encerrando assim, processos de interação de conhecimentos em atuações de aprendizagem reflexivas, amadurecidas e autônomas. 


\section{REFERÊNCIAS}

ARANHA, Maria Lucia de Arruda. História da educação e da pedagogia: geral e do Brasil. São Paulo: Moderna, 2006.

BACICH, Lilian; TANZI NETO, Adolfo; TREVISANI, Fernando de Mello. Ensino híbrido: personalização e tecnologia na educação. In: BACICH, Lilian; TANZI NETO, Adolfo; TREVISANI, Fernando de Mello. (Orgs.). Ensino híbrido: personalização e tecnologia na educação. Cap. 2. Porto Alegre: Penso, 2015.

BASTOS, Celso da Cunha. Metodologias ativas. 2006. Disponível em: <http://educacaoemedicina.blogspot.com.br/ 2006/02/metodologias-ativas.html>. Acesso em: 23 mai. 2016.

BAUMAN, Zygmunt. A modernidade líquida. Rio de Janeiro: Zahar, 2001.

BENDER, William N. Aprendizagem baseada em projetos: Educação diferenciada para o século XXI. Porto Alegre: Penso, 2014.

BERBEL, Neusi Aparecida Navas. As metodologias ativas e a promoção da autonomia em estudantes. In: Artigo da Revista Semina: Ciências Sociais e Humanas, Londrina, v. 32, n. 1, p. 25-40, jan./jun. 2011.

BORDENAVE, Juan Díaz; PEREIRA, Adair Martins. Estratégias de ensino-aprendizagem. 3 ed. Petrópolis: Vozes, 1982.

CARNEIRO, Virgínia Bastos. Metodologias ativas no processo de ensino e aprendizagem: a autonomia discente. Disponível em: <http://www.biblioteca.pucpr.br/pergamum/biblioteca/img.php?arquivo=/00006d/00006dd7.pdf> . Acesso em: 18 nov. 2018.

CASTELLS, Manuel. A sociedade em rede. São Paulo: Paz e Terra, 1999. 698 p.

DEWEY, John. Democracia e educação: capítulos essenciais. São Paulo: Ática, 2007.

. Vida e educação. São Paulo: Melhoramentos, 1978.

. Teoria da vida moral. São Paulo: IBRASA, 1964.

FREIRE, Paulo. Pedagogia da autonomia. 50. ed. Rio de Janeiro: Paz e Terra, 2015.

HOUAISS. Dicionário Houaiss da língua portuguesa. Rio de Janeiro: Editora Objetiva, 2001.

KRAJCIK, Joseph S.; BLUMENFELD, Phyllis C. Project-based learning. In: SAWYER, R. Keith. (Ed.). The Cambridge Handbook of the Learning Sciences. Cambridge University Press, 2006.

LOURENÇO FILHO, Manuel Bergström. Introdução ao estudo da Escola Nova. São Paulo: Melhoramentos, 1950.

MARTINS, Ângela Maria. Autonomia e educação: a trajetória de um conceito. Caderno de pesquisa, n. 115, p. 207232, mar. 2002.

MORAES, Maria Cândida. O paradigma educacional emergente. Campinas: Papirus, 1997. 239 p.

MORAN, José. Mudando a educação com metodologias ativas. In: Coleção mídias contemporâneas. Convergências midiáticas, educação e cidadania: aproximações jovens. UEPG, 2015.

MORIN, Edgar. Os sete saberes necessários à educação do futuro. São Paulo: Cortez; Brasília, DF: UNESCO, 2011.

PIRES, Carla Fernanda Ferreira. O estudante e o ensino híbrido (depoimento). In: BACICH, Lilian; TANZI. Ensino híbrido: personalização e tecnologia na educação. [S.l.: s.n., s/d].

PRENSKY, Marc. Nativos digitais, imigrantes digitais. On the Horizon: MCB University Press, v. 9, n. 5, out. 2001.

RIBEIRO, L.R. C. Aprendizagem baseada em problemas (PBL): uma experiência no ensino superior (online). São Carlos: EduFSCar. 2008. Disponível em: SciELO Books <http://books.scielo.org>. Acesso em: 17 nov. 2016.

ROSSINI, T.S.S.; SANTOS, E. Recursos Educacionais Abertos: Desafios para a autoria e formação de professores na ciberculcura. In: TORRES, Patrícia Lupion. (Org.). Redes e Mídias Sociais. Curitiba: Appris, 2015.

SANTAELLA, L. A aprendizagem ubíqua substitui a educação formal. Revista de Educação e Tecnologia da PUCSP, v. 6, n. 12, p.17-22, jul./dez. 2009.

Comunicação Ubíqua. Representações na cultura e na educação. São Paulo: Paulus, 2013. 
SMITH, Mark K. Jerome S. Bruner and the process of education. The encyclopedia of informal education. Fev 2004. Disponível em: <http://www.infed.org/thinkers/ bruner.htm> Acesso em: 17 nov. 2016.

TORRES, Patrícia Lupion; HILU, Luciane; SIQUEIRA, Lilia Maria Marques. Formando professores universitários para o uso de redes sociais na aprendizagem. In: MIGUEL, Maria Elisabeth Blanck; FERREIRA, Jacques de Lima. (Orgs.). Formação de professores: história, políticas educacionais e práticas pedagógicas. Curitiba: Appris, 2015.

O Laboratório on-line de aprendizagem: uma proposta crítica de aprendizagem colaborativa para a educação. Tese (Doutorado em Engenharia de Produção) - Programa de Pós-Graduação em Engenharia de Produção da Universidade Federal de Santa Catarina, Florianópolis, 2002. Acesso em: 03 set. 2017.

; IRALA, Esrom Adriano F. Aprendizagem colaborativa: teoria e prática. In: TORRES, Patrícia Lupion. (Org.). Algumas vias para estabelecer o pensar e o agir. Curitiba: SENAR-PR, 2007.

. Redes e conexões para compor os liames do conhecimento. In: ANDREOLI, Cleverson V.; TORRES, Patrícia Lupion. (Org.). Complexidade: redes e conexões do ser sustentável. Curitiba: SENARPR, 2014. v. 1. p. 15-32.

TRINDADE, Rui; COSME, Ariana. Educar e aprender na escola: questões, desafios e respostas pedagógicas. Porto: Fundação Manuel Leão, 2010.

. O movimento da educação nova e a reinvenção da escola: da afirmação de uma necessidade aos equívocos de um desejo. Porto: Universidade do Porto, 2012.

WESTBROOK, Robert B.; TEIXEIRA, Anísio. John Dewey. Recife, PE: Editora Massangana, 2010. [Coleção Educadores] 


\section{RESUMO}

O presente artigo trata da autonomia discente em J ohn Dewey e sua atualidade na prática das metodologias ativas no cenário educacional contemporâneo e na participação ativista em rede. O tema "Autonomia discente na universidade: metodologias ativas e a cibercultura" teve como objetivo geral refletir a perspectiva do desenvolvimento de um aluno autônomo com o aprender. Dentre os autores pesquisados estão TORRES, HILU, SIQUEIRA (2015); TRINDADE (2012). Pôde-se inferir que nas metodologias ativas hoje aplicadas em sala de aula, encontram-se pressupostos de autonomia discente em Dewey, na medida em que a valorização do aluno como centro do aprendizado no trabalho em grupos, além do trabalho individual, é estimulada em ambiente educacional democrático.

Palavras-chave: Autonomia discente. Ambiente educacional democrático. Metodologias ativas.

\section{STUDENT AUTONOMY AT UNIVERSITY: ACTIVE METHODOLOGIES AND CYBERCULTURE}

\section{ABSTRACT}

The present article deals with the student autonomy in John Dewey and its actuality in the practice of the active methodologies in the contemporary educational scene and in the activist participation in network. The theme \&quot; Student autonomy at university: active methodologies and cyberculture\&quot; had as objective to reflect the perspective of the development of an autonomous student with the learning. Among the authors researched are TORRES, HILU, SIQUEIRA (2015); TRINDADE (2012). It is possible to infer that in the active methodologies currently applied there are assumptions of student autonomy, to the extent that the student\&\#39; s valorization as the center of learning in group work, besides individual work, is stimulated in a democratic educational environment.

Keywords: Student autonomy. Democratic educational environment. Active methodologies.

\section{LA AUTONOMIA DISCENTE EN LA UNINVERSIDAD: METODOLOGÍAS ACTIVAS Y LA CIBERCULTURA}

\section{RESUMEN}

El presente artículo se refiere a la autonomía discente en John Dewey y su actualidad en la práctica de las metodologías activas en el escenario educacional contemporáneo y en la participación activa en red. En este punto de vista el tema "La autonomia discente en la universidad: metodologias activas y la cibercultura" y la meta general ha sido reflexionar sobre la herencia de Dewey de autonomía discente en la actualidad en la práctica de las metodologías activas. La comprensión del tema contemporáneo justifica esta pesquisa. Prestigiosos autores han sido investigados para la elaboración de esta pesquisa como TORRES, HILU, SIQUEIRA (2015); TRINDADE (2012). A medida en que la valoración del alumno como el centro del aprendizaje en el trabajo en equipo, además del trabajo personal, la estimulación en el ambiente educativo democrático.

Palabras clave: Autonomía discente. Ambiente educativo democrático. Metodologías Activas. 